\title{
XLVII. The development of arbitrary functions
}

\author{
Prof. John Perry \& Mr. H. F. Hunt
}

To cite this article: Prof. John Perry \& Mr. H. F. Hunt (1895) XLVII. The development of arbitrary functions, Philosophical Magazine Series 5, 40:247, 506-511, DOI: 10.1080/14786449508620800

To link to this article: http://dx.doi.org/10.1080/14786449508620800

曲 Published online: 08 May 2009.

Submit your article to this journal

Џll Article views: 2

Q View related articles $\sqsubset$ 
the margins come in contact with one another and thus cause a diminution of the total resistance of the grating. Especially the fact that the spacing of the strips should have so large an influence as to reduce the effect almost to nothing seems to me to favour the above supposition. Also the fact that the change of resistance depends upon the orientation of the strips seems to point in the same direction. Still another fact which is equally important from the above point of view is that the resistance of the tinfoil grating once diminished by an exposure to the action of electric waves can be restored nearly to the original value by tapping the grating. It may be pointed out that Prof. Minchin's experiment ${ }^{*}$ on the action of electromagnetic radiation on films containing metallic powders may stand in close connexion with the present subject.

XLVII. The Development of Artitrary Functions.

By Prof. John Perry and Mr. H. F. Hunt†.

GTUDENTS at the Finsbury Technical College have for $\mathcal{S}$ some years carried out the Fourier development idea of the late Professor Clifford by practical Geometrical methods. The curve which graphically represents the function is supposed to be wrapped round a circular cylinder, and the areas of its projections upon two diametral planes enable the coefficients to be found. In 'The Electrician' of June 28th, 1895, one of us gave detailed instructions for carrying out the process. We do not know of any method of development in a Fourier series which can compare with this in either rapidity or accuracy.

In the discussion of Prof. Henrici's paper, April 13th, 1894, one of us described a graphical method of developing any arbitrary function in a series of other normal forms than sines and cosines, such as Bessels or Zonal Spherical Harmonies. It consisted in wrapping the curve which represents the function round a specially shaped cylinder, not circular, and projecting it upon a certain plane. One of us has wasted many months in finding with great exactness a sufficient number of coordinates of the trace of the cylinder suitable for a Zeroth Bessel development. The labour was unnecessary because the coordinate most troublesome to calculate is not really needed: that is, the actual shape of the cylinder is

* Phil. Mag. [5] xxxvii. p. 90 (1894).

+ Communicated by the Physical Society : read October 25, 1895. 
not needed, and indeed it is better to put aside altogether the idea of a curve being wrapped round a cylinder.

To develop any arbitrary function of $x$ (let us call it $y$ ) in normal forms, the real difficulty consists in finding the value of an integral such as $\int_{0}^{a} y \cdot Q(x) \cdot d x$, where $Q(x)$ is some tabulated function. If now $z$ is another tabulated function which is the integral of $Q(x)$ the required integral is $\int y . d z$.

Suppose the values of $y$ for 25 equidistant values of $x$ to be known, from $x=0$ to $x=a$ (that is, $a$ is divided into 24 equal parts). Let the corresponding values of $z$ be also tabulated, and let a curve be drawn with the values of $y$ as ordinates and the values of $z$ as abscissæ ; the area between this curve and the axis of $z$ gives the value of the integral required.

To illustrate the method we shall show how it is applied in a well-known kind of problem. An arbitrary function $y=f(r)$ of $r$ from $r=0$ to $r=a$ is to be developed in Zeroth Bessels ; that is, we must determine the constants $A_{1}, A_{2}$, \&c., in

$$
f(r)=\mathrm{A}_{1} \mathrm{~J}_{0}\left(\mu_{1} r\right)+\mathrm{A}_{2} \mathrm{~J}_{0}\left(\mu_{2} r^{r}\right)+\& c .+\mathrm{A}_{s} \mathrm{~J}_{0}\left(\mu_{\mathrm{s}} r\right)+\& c .,
$$

where $\mu_{1}, \mu_{2}, \&$ c., are the successive roots of

$$
J_{0}(\mu a)=0 . . \quad \cdot \quad . \quad . \quad .
$$

Now it is well known that

$$
\mathrm{A}_{s}=\frac{2}{a^{2}\left[\mathrm{~J}_{1}\left(\mu_{s} a\right)\right]^{2}} \int_{0}^{a} r f(r) \mathrm{J}_{0}\left(\mu_{s} r\right) \cdot d r ; .
$$

or, letting $\mu_{s} r=x,(3)$ becomes

$$
\mathrm{A}_{s}=\frac{2}{a^{2}\left[J_{1}\left(\mu_{s} a\right)\right]^{2}} \frac{1}{\mu_{s}^{2}} \int_{0}^{\mu_{s} d} x f(x) \mathrm{J}_{0}(x) \cdot d x
$$

Now

$$
\int x \cdot \mathrm{J}_{0}(x) \cdot d x=x \cdot \mathrm{J}_{1}(x),
$$

which is easily found for any value of $x$.

To evaluate the integral in (4), take the 25 equidistant values of our function from 0 to $a$ and use them as the ordinates of points in a curve. The values of the corresponding abscissæe are obtained in the following way. The values of $\mu_{1} \alpha \& c$. are the successive roots of $J_{0}(\mu a)=0$, and are

$\mu_{1} a=2 \cdot 40483$

$\mu_{2} a=5 \cdot 52008$

$\mu_{3} a=8.65373$

$\mu_{4} a=11 \cdot 79153$

and so on.
Take 25 equidistant values of $x$ beginning with 0 and ending with the value $\mu_{s} a$ : the corresponding values of $x \mathrm{~J}_{1}(x)$ are the abscissæ of points in the curve required to find $A_{s}$. 
The area of the curve is easily obtained l,y means of the planimeter. Having found the 25 abscissa once for all, they may be used for the development of any arbitrary function of $r$ of which 25 equidistant values are given. We now publish. four tables giving these abscissæ, which we have carefully calculated for the first four terms of any such development.

In the column headed $\mathrm{P}$ we give the number of the point in the curve of which $x \mathrm{~J}_{1}(x)$ is the abscissa, there being 25 such points altogether. In Table I. the point 24 corresponds to $x=2 \cdot 40483$. In Table II. the point named 24 corresponds to $x=5.52008$, and so on.

In Table II. an additional abscissa is given corresponding to some unknown point between numbers 10 and 11 ; this is the extreme abscissa of the curve, and the corresponding ordinate would be a tangent to the curre. In Table III. there are two additional or bounding abscisse and in Table IV. there are three of them.

TARLE I.

\begin{tabular}{|c|c|}
\hline P. & $x, \mathrm{~J}_{1}(x)$ \\
\hline 0 & 0.0000 \\
\hline 1 & .0050 \\
\hline 2 & 0200 \\
\hline 3 & .0450 \\
\hline 4 & $\cdot 0787$ \\
\hline 5 & $\cdot 1216$ \\
\hline 6 & $\cdot 1727$ \\
\hline 7 & .2312 \\
\hline 8 & .2962 \\
\hline 9 & 3667 \\
\hline 10 & $\cdot 4416$ \\
\hline 11 & .5197 \\
\hline 12 & 5999 \\
\hline 13 & 6807 \\
\hline 14 & 7609 \\
\hline 15 & .8392 \\
\hline 16 & .9142 \\
\hline 17 & .9845 \\
\hline 18 & 1.0490 \\
\hline 19 & $1 \cdot 1062$ \\
\hline 20 & $1 \cdot 1552$ \\
\hline 21 & $1 \cdot 1949$ \\
\hline 22 & $1 \cdot 2242$ \\
\hline 23 & $1 \cdot 2423$ \\
\hline 24 & $1 \cdot 2485$ \\
\hline
\end{tabular}

TÁBLE II.

\begin{tabular}{|c|c|}
\hline P. & $x . \mathrm{J}_{1}(x)$ \\
\hline 0 & 00000 \\
\hline 1 & +0267 \\
\hline 2 & $\cdot 1010$ \\
\hline 3 & 2943 \\
\hline 4 & 3800 \\
\hline 5 & .5578 \\
\hline 6 & 7458 \\
\hline$\tau$ & .0191 \\
\hline 8 & 1.0706 \\
\hline 9 & $1 \cdot 1825$ \\
\hline 10 & 12417 \\
\hline 11 & $1 \cdot 2160$ \\
\hline 12 & $1 \cdot 1141$ \\
\hline 13 & 9418 \\
\hline 14 & 7052 \\
\hline 15 & +133 \\
\hline 16 & +.0791 \\
\hline 17 & -2801 \\
\hline 18 & .6455 \\
\hline 19 & 9963 \\
\hline 20 & $1 \cdot 3118$ \\
\hline 21 & 1.5723 \\
\hline 22 & 17605 \\
\hline 23 & $1 \cdot 8626$ \\
\hline 24 & 1.8783 \\
\hline $10 \mathrm{~A}$ & $1 \div 285$ \\
\hline
\end{tabular}


TABLE III.

\begin{tabular}{|c|c|}
\hline P. & $x, \mathrm{~J}_{1}(x)$ \\
\hline 0 & 0.0000 \\
\hline 1 & +.0640 \\
\hline 2 & $-24: 34$ \\
\hline 3 & $\cdot 5036$ \\
\hline 4 & 7921 \\
\hline 5 & 9485 \\
\hline 6 & $1 \cdot 21.95$ \\
\hline 7 & 1.2395 \\
\hline 8 & $1 \cdot 0986$ \\
\hline 9 & 8366 \\
\hline 10 & +.3353 \\
\hline 11 & -2107 \\
\hline 12 & .7807 \\
\hline 13 & $1 \cdot 2957$ \\
\hline 14 & $1-6788$ \\
\hline 15 & 1.8667 \\
\hline 16 & 1.8195 \\
\hline 17 & $1 \cdot 5279$ \\
\hline 18 & 1.0163 \\
\hline 19 & -3817 \\
\hline 20 & +-4154 \\
\hline 21 & $1 \cdot 156 \mathrm{l}$ \\
\hline 22 & $1 \cdot 7807$ \\
\hline 23 & 22102 \\
\hline 24 & 23490 \\
\hline $6 \mathrm{~A}$ & $+1 \cdot 2485$ \\
\hline $1.5 \mathrm{~A}$ & -1.8783 \\
\hline
\end{tabular}

Table IV.

\begin{tabular}{|c|c|}
\hline P. & $x, \mathrm{~J}_{1}(x)$ \\
\hline 0 & 0.0000 \\
\hline 1 & +1171 \\
\hline 2 & $\cdot 4268$ \\
\hline 3 & 8168 \\
\hline 4 & 1.1373 \\
\hline 5 & $\tilde{1} \cdot 2468$ \\
\hline 6 & 1.0555 \\
\hline 7 & +5001 \\
\hline 8 & $-\cdot 1542$ \\
\hline 9 & .9246 \\
\hline 10 & 1.5554 \\
\hline 11 & 1.8658 \\
\hline 12 & $1 \cdot 7443$ \\
\hline 13 & 1·1825 \\
\hline 14 & -2851 \\
\hline 15 & +7485 \\
\hline 16 & 1.6705 \\
\hline 17 & 22544 \\
\hline 18 & $2: 3065$ \\
\hline 19 & 18114 \\
\hline 20 & +8497 \\
\hline 21 & -3674 \\
\hline 22 & 1.5548 \\
\hline 23 & 24214 \\
\hline 24 & 27410 \\
\hline $4 A$ & +12485 \\
\hline $10 \mathrm{~A}$ & -1.8783 \\
\hline $17 \mathrm{~A}$ & +23490 \\
\hline
\end{tabular}

As an example we have taken a function which has the value 1 at the centre of a circle and the value 0 at the circumference, and which at any place is a linear function of the radius. The outer radius $a$ of the circle is 1 .

In fig. 1 the function is shown graphically by the straight line MDD, and the numbered points in this line correspond to 25 equidistant ordinates. In our actual drawing, of which fig. 1 is a reduction, the scale is such that one mit of value of the function corresponds to 10 inches.

The distances from 0 to any number in the axis of abscissæ ON represented in inches ten times the corresponding values of $x \mathrm{~J}_{1}(x)$ of Table $\mathbf{I}$. Projecting vertically from any point in $\mathrm{ON}$, and horizontally from the corresponding point in DD we obtained points in the curve MBB. We use inches because British planimeters usually measure areas in square inches. We found the area OMBBNO to be 6117 square inches, and as both coordinates were magnified ten times, the Phil. Mag. S. 5. Vol. 40. No. 247. Dee 189.5. $2 \mathrm{~N}$ 
The Development of Arbitrary Functions.

Fig. 1.

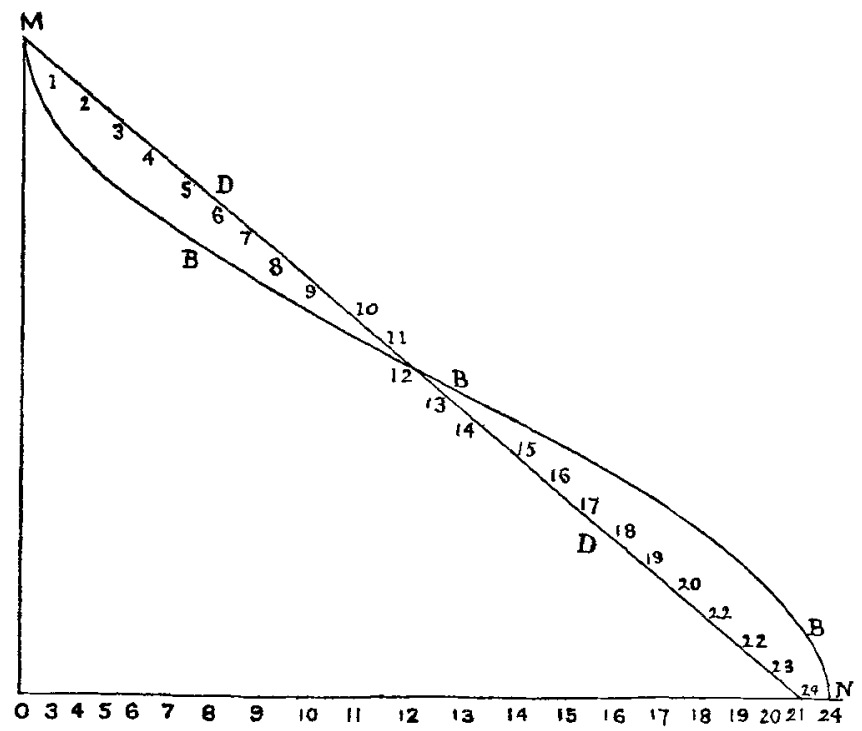

Fig. 2.

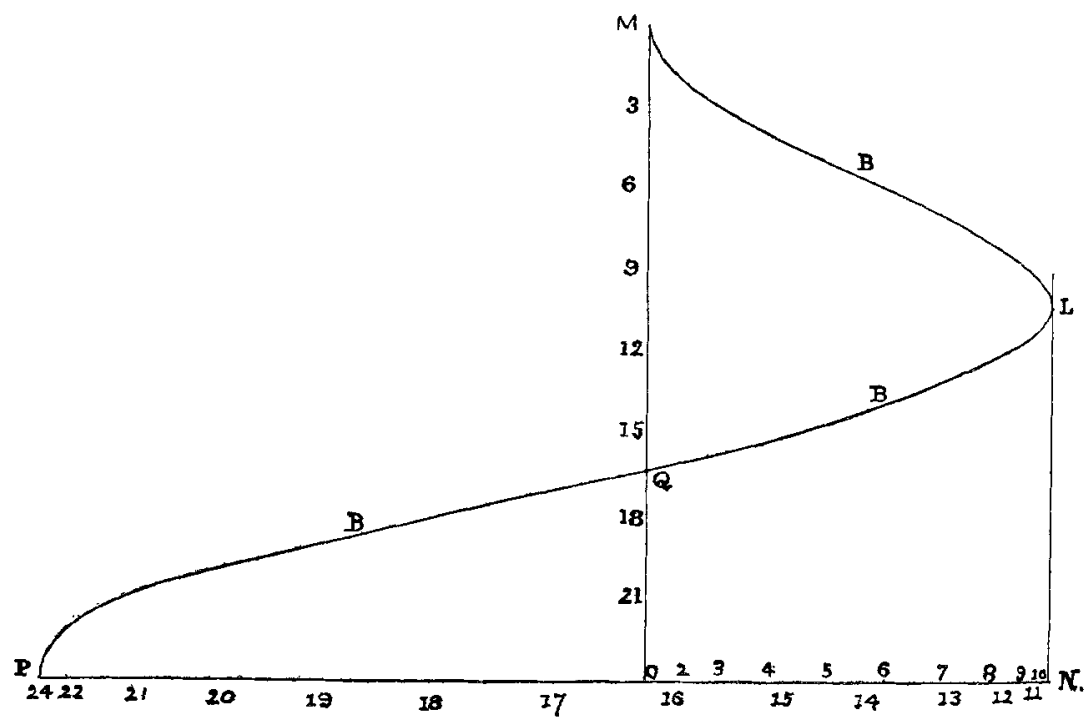


The Atom and the Charge of Electricity carried by it. 511 value of the integral in (4) or

$$
\int_{0}^{2 \cdot 40483} x f(x) J_{0}(x) \cdot d x=0 \cdot 6117
$$

and hence by (4), as $J_{1}(2 \cdot 40483)=0 \cdot 519$,

$$
\mathrm{A}_{1}=\frac{2 \times 0 \cdot 6117}{(0 \cdot 519)^{2}(2 \cdot \overline{405})^{2}}=0.7852 \text {. }
$$

To find $A_{2}$. The 25 equidistant ordinates of the original curve (straight line) are the ordinates of points in the curve MBLBBP (fig. 2), the abscissæ being taken from Table II. We found it convenient to multiply the abscissæ by 5 and represent in inches. Our ordinates were multiplied by 10 and represented in inches. The actual area was 2.36 square inches and one-fiftieth of this, or 0.0472 , is the value of the integral in (4).

$$
\text { Hence, as } J_{1}(5 \cdot 5201)=\cdot 3403 \text {, }
$$

$$
\mathrm{A}_{2}=\frac{2 \times 0 \cdot 0472}{(0 \cdot 3403)^{2} \times(5 \cdot 5201)^{2}}=0 \cdot 0268 .
$$

We need not show the eurves used in finding $A_{3}$ and $A_{4}$. The area of fig. $\bar{z}$ is the positive area MLNOM minus the area LQPNL, but one need not think about whether an area is positive or negative. It is only necessary to start the planimeter-tracer from the point numbered 0 in every case, and go from 0 to $\mathbb{M}$ and along the curve in the direction of the increasing numbers to 24 , then along the axes of abscissæ, ending at the point 0 from which we started.

XLVIII. The Relation between the Atom and the Charge of Electricity carried by it. By J. J. Тномson, M.A., F.R.S., Professor of Experimental Physics, Cambridge*.

T $\mathrm{N}$ the electrolysis of solutions, the persistency of the sign of the electric charge carried by an ion is almost as marked a feature as the constancy of the magnitude of the charge. Thus the hydrogen ion always carries a positive charge, the chlorine ion a negative one. In the electrolysis of gases, however, the sign of the charges carried by the atoms of the different elements is much more variable: here an atom of hydrogen does not always carry a positive charge, nor an atom of chlorine always a negative one; each of these

* Communicated by the Author.

$2 \mathrm{~N} 2$ 